\title{
La disparition d'Howard Temin, homme et virologiste d'exception
}

\author{
Jean-Luc Darlix
}

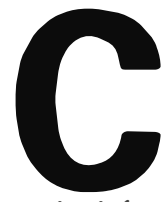

est un grand scientifique, un chercheur doué d'une intelligence et d'une curiosité très vives et toujours en éveil, un homme simple et attentif qui vient de nous quitter à l'âge de 59 ans.

Howard Temin aura marqué son temps, émis des concepts audacieux, révolutionné la biologie moderne et particulièrement la virologie. C'est ainsi qu'en 1964 il émit l'hypothèse du provirus, proposant que la réplication du génome d'un virus à ARN passait par un intermédiaire ADN qui était, ensuite, exprimé par la cellule infectée. En poursuivant ses travaux sur des virus aviaires, il a pu, quelques années plus tard, valider cette hypothèse en découvrant l'enzyme responsable de la réplication du génome ARN simple brin en ADN double brin, l'ADN polymérase dépendante de l'ARN, appelée maintenant reverse transcriptase ou transcriptase inverse. Pendant que Howard Temin décrivait cette enzyme dans des virus infectieux et tumorigènes chez le poulet, David Baltimore, de façon indépendante, faisait la même découverte dans des virus infectieux et tumorigènes chez la souris.

Cette découverte de la transcriptase $\mathrm{m} / \mathrm{s} n^{\circ} 5$ vol. 10, mai 94

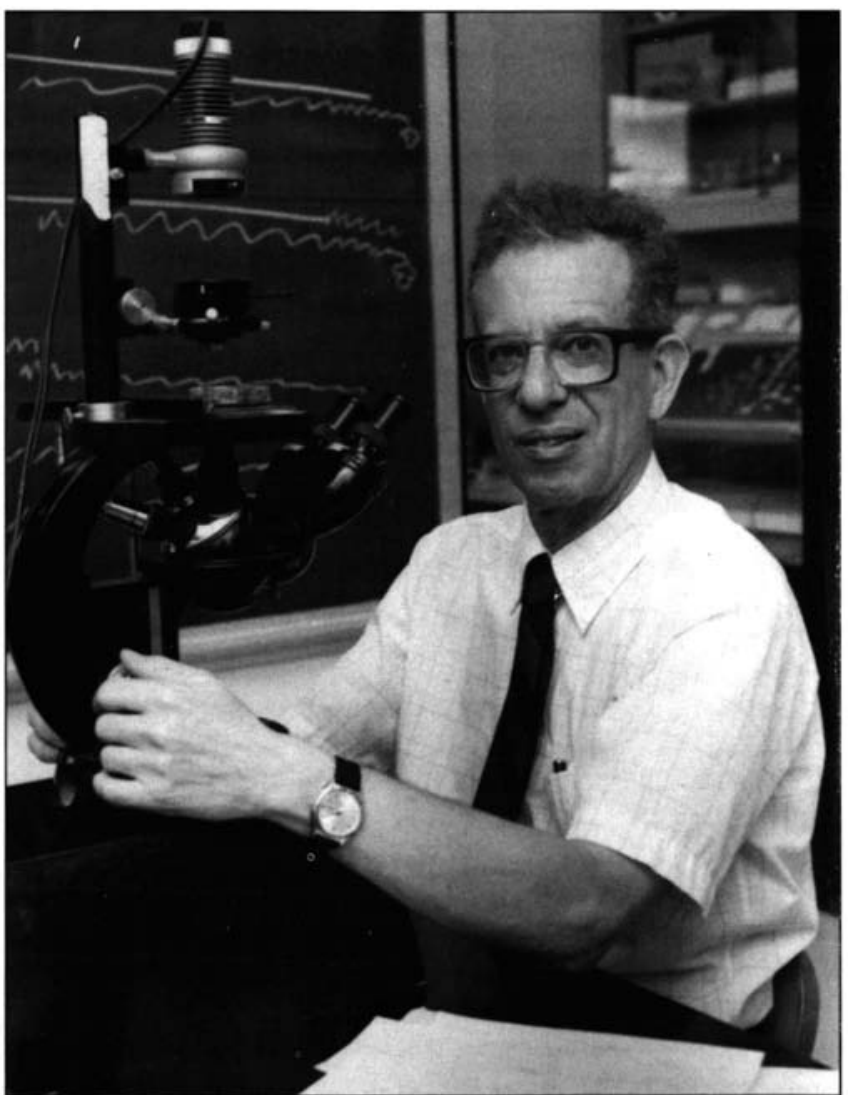

logistes face aux observations qui conduisaient à l'hypothèse du provirus, car elle remettait en cause le dogme central de la biologie, à savoir que le flux de l'information génétique part de l'ADN pour aller à l'ARN puis aux protéines. Ces observations donnaient une nouvelle dimension à la biologie et à la génétique, en indiquant que des informations génétiques pouvaient passer de l'ARN à l'ADN et, éventuellement, faire des allers et retours ARN-ADN. On sait aujourd'hui, grâce à de très nombreux travaux issus de laboratoires américains et européens, que cette $\mathrm{ADN}$ polymérase particulière, la transcriptase inverse, est codée par une classe de virus répandus chez les animaux et l'homme, appelée rétrovirus. C'est aussi grâce à cette activité transcriptase inverse que de nombreux inverse dans des virus aviaires et rétrovirus humains et simiens ont murins, appelés oncovirus car ils été découverts depuis quinze ans, et induisent des cancers chez les animaux infectés, a valu à Howard Temin, David Baltimore et Renato Dulbecco de recevoir le prix Nobel de Médecine en 1975.

Mais ne nous trompons pas, cet honneur rendu à Howard Temin l'a été après bien des années de travail marquées par le scepticisme, et quelquefois la dérision, de certains bio- en particulier les virus humains VIH et HTLV.

Ces observations originales de H. Temin ont été également le point de départ de la découverte d'enzymes analogues à la transcriptase inverse chez des virus comme les hépadnavirus (virus de l'hépatite B chez l'homme, le canard) et les caulimovirus (virus de la mosaï- 
que du chou-fleur). Plus intriguant encore, une séquence codant pour une telle enzyme a aussi été mise en évidence dans des éléments génétiques transposables, les rétrotransposons, dont de nombreuses copies sont présentes dans la plupart des génomes eucaryotes, de la levure à l'homme.

Né en 1934 à Philadelphie, Howard Temin a obtenu son doctorat (Ph D) en 1960 au Califormia Institute of Technology (Pasadena) en travaillant sur des oncovirus sous la direction de Renato Dulbecco. La même année, il rejoignit l'université du Wisconsin pour continuer sa recherche sur les rétrovirus, université où il resta jusqu'à sa disparition.

C'est dans cette université qu'il mit en évidence pour la première fois la transcriptase inverse; découverte féconde puisque, vingt-cing ans plus tard, les travaux de génétique, de biochimie et de biologie structurale continuent pour explorer les moindres secrets de cette enzyme fabuleuse. Car la transcriptase inverse est aussi une enzyme clé en génétique moléculaire pour l'analyse et l'expression des gènes eucaryotes, au travers des processus de synthèse et de clonage des $\mathrm{ADNc}$, ce qui en fait une enzyme indispensable aux industries de biotechnologie.

Howard Temin fut aussi un pionnier dans l'analyse et la compréhension de mécanismes génétiques aussi fondamentaux en virologie que la capture par les rétrovirus de séquences cellulaires par le biais d'événements de recombinaison $\left(m / s, n^{\circ} 4\right.$, vol. 10 , p. 425). Cette capture, ou transduction, correspond au détournement et à la dérégulation de fonctions cellulaires, par et pour le virus, avec la formation de virus au pouvoir fortement oncogénique.

Les rétrovirus possèdent deux copies, identiques ou quelque peu différentes, du génome $\mathrm{ARN}$, ce qui correspond à une diploïdie ou à une pseudo-diploïdie comme aimait à le dire $\mathrm{H}$. Temin. Au moyen de manipulations génétiques $\mathrm{H}$. Temin et ses collaborateurs furent parmi les premiers, au début des années 1980, à construire des vecteurs rétroviraux pour la transgénèse, dérivant du virus de la nécrose de la rate (SNV). En utilisant des génomes rétroviraux recombinants, ils mirent alors au point, pour analyser les événements de recombinaison au niveau moléculaire, un système génétique particulièrement élégant, basé sur la formation de virus hétérozygotes ayant incorporé des génomes recombinants différents. C'est aussi grâce aux rétrovirus recombinants qu'ils purent étudier les mécanismes de la variabilité génétique des rétrovirus. Les résultats, alliant élégance et précision, démontrèrent que la variabilité ainsi que les recombinaisons étaient très élevées chez les rétrovirus, des milliers de fois plus élevées que lors de la réplication d'un génome cellulaire.

Sachant que le génome rétroviral est diploïde, les observations de H. Temin et de ses collaborateurs impliquent que la transcriptase inverse est capable de produire un ADN recombinant unique en copiant alternativement les deux ARN génomiques; cette capacité de changer facilement de matrice serait une autre propriété de la transcriptase inverse. Les recombinaisons se produisent-elles avec la même fréquence chez les rétrotransposons? Et, si oui, quelles en sont les conséquences génétiques? C'est là un immense champ d'études à venir en génétique et biochimie, tant sur les rétrovirus que sur les éléments transposables codant pour une transcriptase inverse.

Voilà quelques-unes des observations scientifiques uniques que nous a laissées Howard Temin, porteuses de tant de curiosité et de travaux à venir, en vérité de superbes fleurs. Il me reste la vision de cet homme mince à l'accent un peu lent et rocailleux, aux yeux vifs, aux questions très directes et pertinentes, et tout à la fois modeste, attentif et très curieux. C'est rare pour un homme scientifique de cette stature

\section{J.-L. Darlix}

École Nonnale Supérieure de Lyon (ENSL), Laboratoire Rétro INSERM, 46, allée d'ttalie, 69364 Lyon Cedex 07, France. 